preted; and that spirit, in the British Zone, is very favourable. Göttingen, one of the few university towns in Germany where war damage has been negligible, has been chosen as scientific headquarters. Here the office of the Research Branch of the Economic Subcommission of the Control Commission has been set up ; its scientific adviser is Dr. R. G. J. Fraser. Plans are under way to create in Göttingen a substitute for the former research centre of Berlin-Dahlem, where a great number of the famous institutes of the Kaiser Wilhelm Gesellschaft were situated, and which no longer exists. The Allgemeine Versuchs-Anstalt (AVA) in Göttingen. is not only using existing buildings but also planning to erect new ones to house institutes for physics, fluid flow, brain research, instrument design, and particularly medical research, to which special assistance will be granted.

The support given by the Research Branch and its officials to German science is by no means confined to the Göttingen complex. A new institute for the standardization of physical quantities, in the tradition of the former Physikalisch-Technische Reichsanstalt, is in course of formation in Volkenrode (near Brunswick). Another sphere of the Research Branch's activities is in the newly created learned societies; because of their official Nazi affiliations the German Physical Society, the German Chemical Society, and many similar ones were disbanded; but a new German Physical Society in the British Zone held its second conference in Göttingen at the beginning of last September (see Nature, November 22, 1947, p. 723), to be followed a month later by a meeting in Bonn of the Society of German Chemists in the British Zone. Both meetings were attended by a number of foreign scientific workers.

It is well known that in certain branches of chemical documentation Germany had been leading for many decades; no reference work on organic chemistry can compare with "Beilstein", none on inorganic chemistry with the eighth edition of "Gmelin", both of which are publications of the German Chemical Society. Both are still incomplete, and it is very gratifying to learn that, after a period of uncertainty following Germany's collapse, provision has now been made for their continuation. "Beilstein" will be re-organised in the American Zone, but some difficulties may be expected owing to the loss of a few of the senior members of the original editorial staff ; "Gmelin", on the other hand, is fortunate in that practically the entire staff is now re-assembled in the British Zone, as the Gmelin Institute for Inorganic Chemistry and Related Subjects. Its new organisation presents some interesting features, so a few more words may not be amiss.

In Clausthal, near Göttingen, buildings of a munition factory had been scheduled to be blown up by the army; thanks to the intervention of the Research Branch, the administrative block was spared, in which at the moment the chief editor of "Gmelin", Prof. E. Pietsch, and about fifty of his old helpers have not only their offices but also living quarters for themselves and their families. The great hardships of life in present Germany are thus mitigated; the housing problem is solved, and the purchase of fuel and food is a community affair. The beneficial influence on the scientific productivity of the "Gmelin" staff is very obvious; and as, fortunately, a photographic copy of the 900,000 odd reference cards which the staff had prepared in the course of twenty years has been saved (although the originals were destroyed by fire), the editor's hope of completing the new edition of "Gmelin" in ten years may well come true.

There is probably no scientific worker in Germany who would not appreciate the help given by the Allies in the revival of the various scientific activities, though some seem to think that the possible control of their work by international committees is no unmitigated blessing. It would certainly be regrettable if control, or even advice, should go so far as to make work appear international which is, in fact, due to the efforts of German specialists. In this connexion we should like to refer again to the very different situation which existed in Germany after the First World War, when the necessity of keeping science in Germany alive by its own exertion, against international detachment or even hostility, proved to be in itself a potent force in its recovery. One can understand that to-day there is in some quarters a slight resentment against too much patronizing from outside; but what seems to some justified national pride may easily be denounced by others as a remnant of Nazism. All the steps taken by the British Control Commission with respect to scientific activities in Germany have to be viewed against a very complex psychological background; considering that such difficulties are added to those due to the hard material conditions, everyone will gladly acknowledge that, thanks to the Research Branch of the Control Commission, a great deal has already been achieved, and that one can cherish very good hopes for the future.

\section{WATER MOVEMENTS AND EARTH CURRENTS : ELECTRICAL AND MAGNETIC EFFECTS*}

TT is a consequence of Faraday's law of electro1 magnetic induction that when a large body of water moves in the presence of the earth's magnetic field, an electromotive force is set up across the direction of motion. Faraday himself said that the tidal streams in the English Channel would generate electric currents across the channel, through the sea, and returning through the land beneath the water. Twenty years later (1851) he was satisfied that fluctuations observed by Charlton Wollaston on the first submarine cable between England and France were due to this effect. Other early observations tended to confirm the connexion of the tides with earth currents in submarine cables and in coastal regions.

No serious study of the subject was made at the time, but a great step forward was made in 1918 when Young, Gerrard and Jevons made a series of experiments with electrodes in the sea at Dartmouth, and Decheverens demonstrated the dependence of the fluctuating earth-current on the tides in one of the Channel Islands. Another striking contribution was made by Cherry and Stovold, who observed fluctuation of tidal periods between the English and French coasts when Post Office cables were being renewed after the Second World War, the largest differences being as much as 0.8 volt. Several Admiralty departments have also observed submarine fluctuations of tidal period, and the subject is being studied

* Substance of papers by N. Barber and M. S. Longuet-Higgins, Admiralty Research Laboratory, read at a Geophysical Discussion the Royal Astronomical Society on November 27. 
at the Admiralty Research Laboratory. A possible application is that once a suitable calibration has been made, the potentials, in sea or land, may serve as a routine method of measuring tidal streams or other water flow.

The gradients are detected by a high-resistance galvanometer the terminals of which are connected to non-polarizing electrodes placed a mile or so apart on the sea bottom, or down wells near the coast. The potential gradients are of the order of 10 millivolts per kilometre. Evidence that the tidal potential gradients and the electric current associated with them are due to the motion of the tidal streams through the earth's magnetic field is provided by the following observations : (1) The potential gradient in the sea is directed approximately at right angles to the direction of water flow. (2) The times of maximum potential gradient coincide with the times of maximum velocity of the tidal stream. (3) The English coast is positive with respect to the French coast when the tidal stream is flowing east. (4) The potential gradient in the land is directed in the opposite sense to the potential gradient in the sea : when the potential of the English coast is positive, the point of highest potential is on the coast and the potential is less at points farther inland or out to sea.

If the moving water in the Channel acts as a tidal dynamo, the electromotive force to be expected can be estimated from the known velocity of the tidal streams and the vertical intensity of the earth's magnetic field. The estimated electromotive force between the English and French coasts at the time of maximum stream is 3 volts, which is about four times as much as the observed potential difference. The reduction can be attributed to the flow of electric current: when the English coast is at a positive potential the current flows northwards through the water, and after spreading outwards and downwards into the land returns in a southward flow below the sea bed, so that the tidal dynamo is short-circuited. In the water the electric current density is estimated to be about $10^{-8}$ amp. per square centimetre when the tidal streams have their maximum velocity; but in the land, and below the sea bed, the current density is presumably very much less.

If the magnetic field produced by this presumed flow of electric current could be measured, it would give further valuable evidence of the phenomenon; but since the flow of current is solenoidal it can be expected to produce little or no magnetic field on the earth's surface. On the sea bed in the English Channel at a depth of 100 metres, the flow of electric current may produce a tidal variation amounting to \pm 10 gamma in the east-west component of magnetic field ; but in the land near the coast at a depth of 1,000 metres the variation of magnetic field may amount to less than 1 gamma, since the current density in the land is so much smaller. No observations of this nature have yet been made.

The observation of tidal potential gradients is usually complicated by more rapid and irregular variation of potential gradient due to earth currents associated with magnetic storms. These earth currents are observed in the sea as well as on land, and they tend to be concentrated in estuaries and channels, presumably because these provide preferential paths of low resistivity.

The magnetic fields of these concentrations make important contributions to the vertical magnetic intensity in the neighbouring coastal regions. This possibility was recognized by Van Bemmelen, who made a survey of the character of the sudden commencement of magnetic storms at a large number of observatories, and showed that the sudden changes of vertical intensity are usually of opposite signs at the Greenwich and Paris Observatories, although the two observatories are only 200 miles apart. He suggested that the difference in sign might be due to earth currents induced by the magnetic storm being concentrated in the English Channel between the two observatories.

An example taken from measurements of the eastwest potential gradient in the sea off Plymouth for a minor magnetic storm with a sudden commencement at $2240 \mathrm{hr}$. on August 30, 1946, when the horizontal intensity changed by 65 gamma in an interval of about three minutes, shows that the east-west potential gradient in the sea increased by 60 millivolts per kilometre at the same time. Assuming that such a potential gradient was present in the whole of the English Channel, it can be inferred that a current of about 3,000 amp. was flowing at the time. Such a current flowing fifty miles from the Observatory at Abinger would produce there a vertical magnetic field of 7 gamma, an appreciable part of the 12 gamma which was actually measured.

Although there is some indication that earth currents localized in the English Channel may produce appreciable magnetic changes at Abinger when the period of the change is as long as an hour, the effect of earth currents should be more important in variations of shorter period. Experiments in the narrow channel between Cumbrae and Bute in the Clyde estuary suggest that earth currents in this and neighbouring channels are the main source of fluctuation of magnetic field as far as periods less than 10 min. are concerned; but for longer periods (greater than $30 \mathrm{~min}$.), the direct magnetic effect of the overhead electric currents becomes of increasing importance relative to that of the earth currents. The study of short-period variations in the earth's magnetic field must, therefore, take account of possible secondary effects due to earth currents concentrated in a channel or arm of the sea.

\section{OBITUARIES \\ Prof. David Enskog}

WE learn only now, with much regret, of the death on June 1, 1947, of David Enskog, professor of mathematics and mechanics at the Kungliga Tekniska Högskolan, Stockholm, since 1930.

Born in 1887, Enskog was a student at Uppsala from 1906 until 1911, in which year he obtained his licentiate, partly for experimental work on gas diffusion. In the same year he published a short paper on the kinetic theory of gases, which contains a brief mention (the first so far as I know) of the phenomenon which since 1916 has been called thermal diffusion. In 1912 he published another paper dealing with a gas composed of electrons and molecules; H. A. Lorentz had shown that the mean free-path phenomena for such a gas could be accurately calculated; for this case Enskog made the first accurate calculation of the thermal diffusion coefficient.

Enskog sought without success to obtain a travelling studentship to enable him to continue his studies and research ; instead he became a schoolmaster, first at Stockholm, and later at Skövde and Gävle. He married in 1913. During the First World War he was 